\title{
Tetrahedral Nature Determines the Stability of Reactive Intermediates: A Chemical Education Perspective
}

\author{
SANJEEV RACHURU ${ }^{*}$, JAGANNADHAM VANDANAPU ${ }^{2 *}$ and SREEDHAR PANDIRI ${ }^{1}$ \\ 'Department of Chemistry, Geethanjali College of Engineering and Technology, \\ Cheeryal-501301, Telangana, India. \\ ${ }^{2}$ Department of Chemistry, Osmania University, Hyderabad 500007, India \\ ${ }^{*}$ Corresponding athor E-mail: rachuru1sanjeev1@ rediffmail.com
}

http://dx.doi.org/10.13005/ojc/350160

(Received: November 16, 2018; Accepted: January 16, 2019)

\begin{abstract}
Hammett equation is applied and the magnitude of substituent effect in terms of Hammett $\rho$ has been estimated for the deprotonation equilibriums of highly unstable arenium ions (Wheland intermediates) $\mathrm{XC}_{6} \mathrm{H}_{6}{ }^{+} \rightleftharpoons \mathrm{XC}_{6} \mathrm{H}_{5}{ }^{+} \mathrm{H}^{+}$based on the attenuation effect of methylene group on the dissociation equilibriums of anilinium ions, benzyl ammonium ions and 2-phenylethyl ammonium ions. The Hammett $\rho$ was found to be 14.3. The Hammett $\rho$ for the deprotonation equilibriums of pyridinium ions $\mathrm{XC}_{5} \mathrm{H}_{4} \mathrm{NH}^{+} \rightleftharpoons \mathrm{XC}_{5} \mathrm{H}_{4} \mathrm{~N}^{+} \mathrm{H}^{+}$was estimated from the plot of log $\mathrm{K}_{\mathrm{a}}$ vs Hammett $\sigma$, this value is 5.90. The magnitude of substituent effect in terms of Taft $\rho^{\star}$ has been estimated for the deprotonation equilibriums of methanium ions $\mathrm{RCH}_{4}{ }^{+} \rightleftharpoons \mathrm{RCH}_{3}{ }^{+} \mathrm{H}^{+}$based on the attenuation effect of methylene group on the dissociation equilibriums of aliphatic amines and was found to be 6.9. The Taft $\rho^{*}$ for the deprotonation equilibriums of alkyl ammonium ions $\mathrm{RNH}_{3}{ }^{+} \rightleftharpoons \mathrm{RNH}_{2}+\mathrm{H}^{+}$was estimated from the plot of $\log \mathrm{K}_{\mathrm{a}}$ vs Taft $\sigma^{*}$, this value is 3.28 . The large differences in the Hammett $\rho$ of 8 units when carbon is replaced with nitrogen as heteroatom in the six-member aromatic ring and 3.6 units of Taft $\rho^{*}$ when carbon is replaced with nitrogen in aliphatic derivatives respectively is explained.
\end{abstract}

\section{INTRODUCTION}

The frequent over viewing and dealing with Hammett and Taft equations is a continuous well documented observation from our laboratory ${ }^{1-16}$. In all these studies application of Hammett and Taft equations is dealt in detail and even to physical properties like dipole moments, surface tensions and melting points of several organic compounds.
But application of Hammett and Taft equations to very unstable intermediates is a challenging task. Application of Hammett and Taft equations to arenium ions ${ }^{10}$ (Wheland intermediates, $\mathrm{XC}_{6} \mathrm{H}_{6}{ }^{+}$) and methanium ions ${ }^{15}$ (super acids, $\mathrm{RCH}_{4}^{+}$) is itself novel. In the present work we tried to explain why the deprotonation equilibriums of arenium ions (Wheland intermediates, $\mathrm{XC}_{6} \mathrm{H}_{6}{ }^{+}$) and methanium ions (super acids, $\mathrm{RCH}_{4}^{+}$) are more susceptible to substituent

This is an Open Access article licensed under a Creative Commons license: Attribution 4.0 International (CC- BY). Published by Oriental Scientific Publishing Company @ 2018

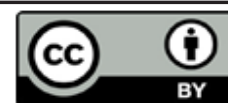


effects than the deprotonation equilibriums of the corresponding nitrogen analogues, the pyridinium ions $\left(\mathrm{XC}_{5} \mathrm{H}_{4} \mathrm{NH}^{+}\right)$and the alkyl ammonium ions $\left(\mathrm{RNH}_{3}^{+}\right)$respectively?

\section{METHODS}

All calculations and curve fittings were done by Kaleida Graph software version 4.1 supplied by Synergy Software INC., Reading, PA, USA. All chemical structures were drawn using "Chemdraw" software.

\section{DISCUSSION}

Arenium ions are formed as unstable intermediates by the attack of a positive ion or a dipole on the benzene ${ }^{17}$. The known simplest arenium ion is the benzenonium ion 1 (scheme 1) with $\mathrm{X}=\mathrm{H}$ prepared in $\mathrm{HF}-\mathrm{SbF}_{5}-\mathrm{SO}_{2} \mathrm{CIF}-\mathrm{SO}_{2} \mathrm{~F}_{2}$ at $-134^{\circ} \mathrm{C}$ by Olah group ${ }^{18}$.<smiles>[X]c1ccccc1</smiles><smiles>[X]c1ccc[nH+]c1</smiles>

Scheme 1

In fact not all chemical species are readily open to experimental characterization. Determination of any physical property like Hammett reaction constant $(\rho)$, from the plot of pKa $\left(-\log \mathrm{K}_{\mathrm{a}}\right)$ versus Hammett $\sigma$ of these benzenonium ions is extremely difficult. It may be possible by time resolved optical methods which is very expensive and time consuming. We have achieved a simple and lucid protocol and is presented in our earlier ${ }^{10}$ article for the evaluation of the Hammett reaction constant $(\rho)$ of the deprotonation process of these benzenonium (arenium) ions $\mathrm{XC}_{6} \mathrm{H}_{6}{ }^{+} \rightleftharpoons \mathrm{XC}_{6} \mathrm{H}_{5}+\mathrm{H}^{+}$based on the attenuation effect of methylene group on the dissociation equilibriums of anilinium ions, benzyl ammonium ions and 2-phenylethyl ammonium ions. Using the pKa values of anilinium ions, benzyl ammonium ions and 2-phenylethyl ammonium ions the Hammett $\rho$ values were first estimated for the three equilibriums from the plot of log Ka versus Hammett $\sigma$. Then using the equation $\rho=m_{1}{ }^{(2-i)}$ from Andrew Williams treatment ${ }^{19}$, the Hammett $\rho$ is determined for the deprotonation process of arenium ions $\mathrm{XC}_{6} \mathrm{H}_{6}{ }^{+} \rightleftharpoons \mathrm{XC}_{6} \mathrm{H}_{5}+\mathrm{H}^{+}$for $\mathrm{i}=0$, from the interpolation of the locus of the plot of Hammett $\rho$ versus 'i' where 'i', the number atoms (number of $-\mathrm{CH}_{2}$ - groups) between the ionizable proton and the ring carbon atom (Fig. 1) and it was found to be 14.3.

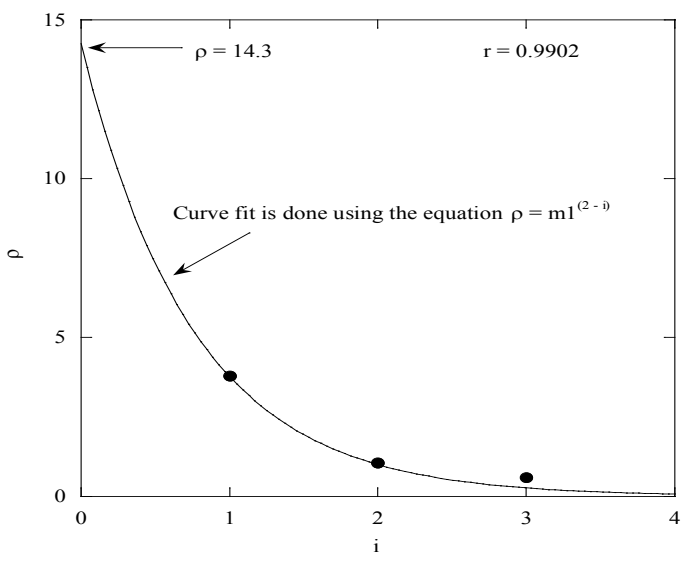

Fig. 1. Plot of Hammett $\rho$ versus $i$ (the number of atoms between the ionizable proton and the ring carbon)

The Hammett $\rho$ for the deprotonation equilibriums of pyridinium ions

$\mathrm{XC}_{5} \mathrm{H}_{4} \mathrm{NH}^{+} \rightleftharpoons \mathrm{XC}_{5} \mathrm{H}_{4} \mathrm{~N}+\mathrm{H}^{+}$

was estimated from the plot of $\log \mathrm{K}_{\mathrm{a}}$ vs Hammett $\sigma$, this value is found to be 5.90 , Figure 2)

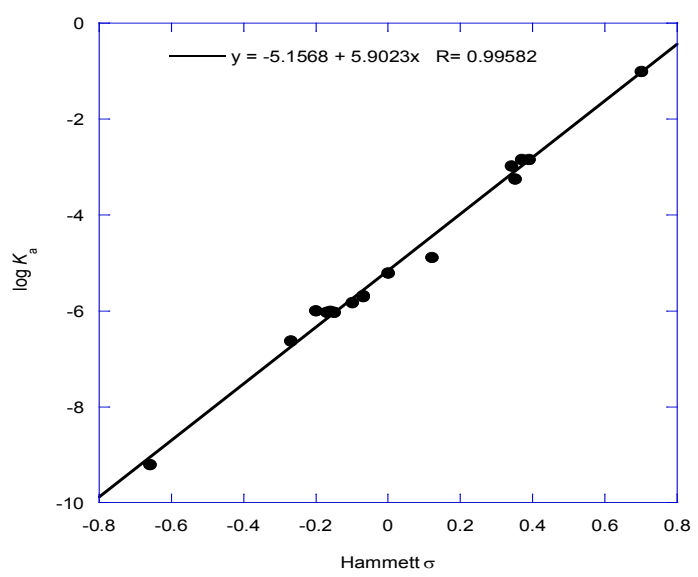

Fig. 2. Plot of log Ka vs Hammett sigma of pyridines

The magnitude of substituent effect in terms of Taft $\rho^{*}$ has been estimated for the deprotonation equilibriums of methanium ions $\mathrm{RCH}_{4}^{+} \rightleftharpoons \mathrm{RCH}_{3}+$ $\mathrm{H}^{+}$again using William's treatment ${ }^{19}$ based on the attenuation effect of methylene group on the 
dissociation equilibriums of aliphatic amines and was found to be 6.9 (Figure 3).

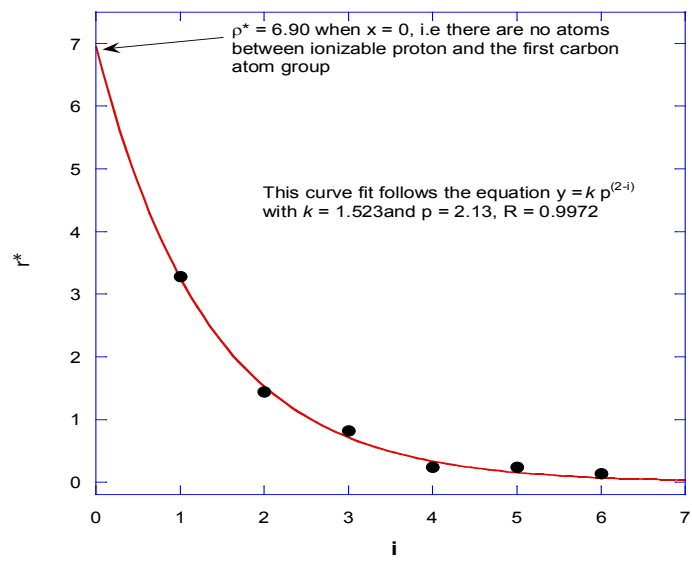

Fig. 3. Plot of $r^{*}$ versus "i" the number of atoms between ionizable proton and the first carbon atom of the alkyl substituent

The Taft $\rho$ * for the deprotonation equilibriums of alkyl ammonium ions $\mathrm{RNH}_{3}{ }^{+} \rightleftharpoons \mathrm{RNH}_{2}+\mathrm{H}^{+}$was estimated from the plot of $\log \mathrm{K}_{\mathrm{a}}$ vs Taft $\sigma^{\star}$ and was found to be 3.28 (Figure 4).

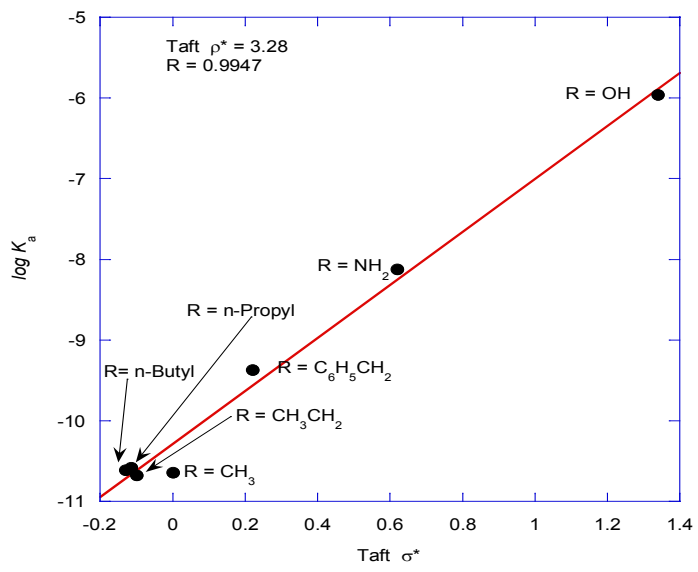

Fig. 4. Plot of $\log K$ versus Taft $\sigma^{*}$ values of alkyl ammonium ions $\left(\mathrm{RNH}_{3}^{+}\right)$with one atom between ionizable proton and the first carbon atom of the substituent

The large decrease in the Hammett $\rho$ of 8 units when carbon is replaced with nitrogen as hetero atom in the six-member aromatic ring and 3.6 units of Taft $\rho^{*}$ when carbon is replaced with nitrogen in aliphatic derivatives respectively is explained as follows:

The formation and deprotonation of 1 is well discussed ${ }^{17}$. The discernible difference between the formation of benzenonium ion 1 and pyridinium ion 2 is the loss of aromaticity of benzene and yet still retention of aromaticity of pyridine respectively. The octet of one of the three carbons 2, 4 and 6 in benzenonium ion 1 (scheme 2) in which to the carbon 1 the proton is attached is incomplete. At any given point of time one of the three carbons carries the positive charge and the octet is incomplete. Pyridinium cations 2 are aromatic ions, as determined by Hückel's rule ${ }^{20}$. It is isoelectronic to benzene. The octet of nitrogen in pyridinium ion is still intact. Therefore in terms of stability, pyridinium ion 2 is more stable than the benzenonium ion 1.

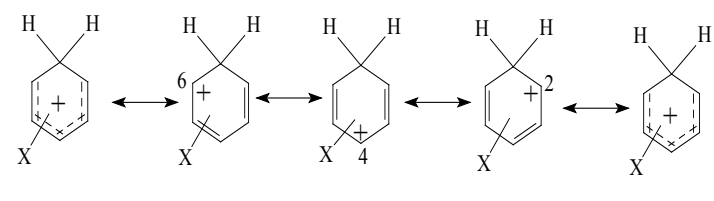

Scheme 2

Another important point to note is the difference in the hydrophilic character of carbon and nitrogen. It is a well recognized fact that ammonia $\left(\mathrm{NH}_{3}\right)$ is more hydrophilic than methane $\left(\mathrm{CH}_{4}\right)^{21}$. An example of this is the presence of nitrogen in a $\mathrm{sp}^{2}$ carbon frame work increases the hydrophilic character of carbon nano tubes because $\mathrm{N}$-doped carbon nano tubes are more polar than neat carbon nano tubes ${ }^{22,23}$. The higher the polarity the more favorable will be the interaction of a substance with hydrophilic solvents like water. Pyridine is nothing but a molecule with nitrogen in a $\mathrm{sp}^{2}$ carbon frame work. Therefore in terms of stability and hydrophilicity, among the transition states during the formation of arenium ions and pyridinium ions, the transition states of pyridinium ions are more hydrophilic, hence solvated by water more efficiently and are therefore more stable. In effect, hydrogen bonding to the nitrogen in pyridinium ion partially quenches the unit positive charge on nitrogen. Consequently, the Hammett $\rho$ value is less than that for arenium ions deprotonation equilibrium. The nitrogen in pyridium ion is tertiary and it is known that the tertiary nitrogen ions are more effectively hydrated/solvated than the bare nitrogen in tertiary amines ${ }^{24,25,26}$. Invoking reactivity-selectivity principle ${ }^{27}$ the more stable species is less susceptible to any other effect exerted on it. Therefore the substituent effects on the depronation equilibriums of pyridinium ions are less than those of the arenium ions. This is reflected on the Hammett $\rho$ values of both the deprotonation equilibriums. The Hammett $\rho$ value of 14.3 of arenium ion deprotonation equilibriums is more than the value of 5.9 of pyridinium ions. 
Similar is the situation with methanium ions and alkylammonium ions. Again the perceptible difference between methanium ion 3 and alkylammonium ion 4 is the loss of tetrahedral nature of methane on protonation and yet the intactness of the tetrahedral nature of alkyl amine even after formation of alkyl ammonium ion (scheme 3).

Invoking all the arguments offered for the arenium and pyridinium ions above, it can be inferred that the Taft $\rho^{*}$ value of 6.9 for the deprotonation equilibriums of methanium ions is greater than that of 3.28 for the alkylammoinium ions.

\section{CONCLUSION}

The deprotonation equilibriums of arenium ions (Wheland intermediates, $\mathrm{XC}_{6} \mathrm{H}_{6}{ }^{+}$) and methanium ions (super acids, $\mathrm{RCH}^{+}$) are more susceptible to substituent effects than the deprotonation equilibriums of pyridinium ions $\left(\mathrm{XC}_{5} \mathrm{H}_{4} \mathrm{NH}^{+}\right)$and alkyl ammonium ions $\left(\mathrm{RNH}_{3}{ }^{+}\right)$respectively. This is explained on the basis of the retention of the tetrahedral nature of

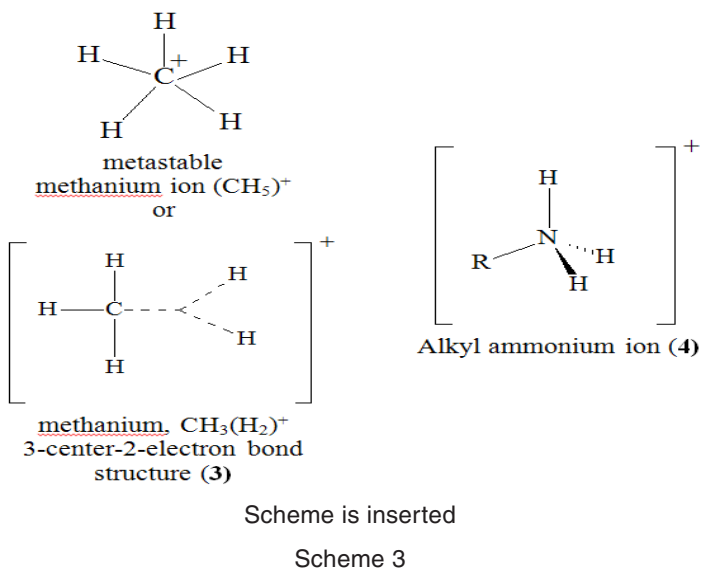

the alkyl amines even after the formation of the respective alkyl ammonium ions on protonation. But on protonation the tetrahedral nature of methane is lost after formation of methanium ion.

\section{ACKNOWLEDGEMENT}

This research did not receive any specific grant from funding agencies in the public, commercial, or not-for-profit sectors.

\section{REFERENCES}

1. Vandanapu, J. Bulgarian Chem. Commns., 2009, 41, 50-53.

2. Vandanapu, J. Chemical Education Journal., 2009, 12, 1.

3. Vandanapu, J. Physical Chemistry., 2010, 26.

4. Rachuru, S.; Vandanapu, J.; Rachuru V.V; Education Journal., 2012, 1, 1-4.

5. Rachuru, S.; Vandanapu, J.; Rachuru V.V; The Bulgarian Journal of Chemical Education., 2012, 21, 71-76.

6. Rachuru, S.; Vandanapu, J.; Rachuru V.V; ChemEdNZ., 2012, 14, 1-4.

7. Rachuru, S.; Vandanapu, J.; Rachuru V.V; Advances in Physical Chemistry., 2012, 141-4.

8. Rachuru, S.; Vandanapu, J.; ChemXpress., 2012, 1, 8-9.

9. Rachuru, S.; Vandanapu, J.; Rachuru V.V; World Journal of Chemical Education., 2013, 1, 1-5.

10. Rachuru, S.; Vandanapu, J.; Rachuru V.V; Bulgarian Chem. Commns., 2014, 46, 375-378.

11. Rachuru, S.;Vandanapu, J.;Skelton, A.A;Rachuru V.V; Chem. Educator., 2014, 19327-329.
12. Rachuru, S.; Vandanapu, J.; Skelton, A.A; Rachuru V.V; Research Journal of Chemistry \& Environment., 2015, 19, 24-28.

13. Rachuru, S.; Vandanapu, J.; Skelton, A.A; Rachuru V.V; Asian Journal of Chemistry., 2015, 27, 3297-3299.

14. Rachuru, S.;Vandanapu, J.; Skelton, A.A; Journal of Molecular Liquids., 2016, 224, 43-46.

15. Rachuru, S.; Vandanapu, J.; Current Physical Chemistry., 2017, 7, 218-221.

16. Rachuru, S.; Vandanapu, J.; Skelton, A.A.; Bethapudi, V.E.M.M.; Pandiri, S.; Rachuru V.V; Orient. J. Chem., 2017, 33, 2292-2296.

17. March J 1992 Advanced Organic chemistry: Reactions, Mechanisms and Structure", John Wiley \& Sons $4^{\text {th }}$ Edition 502.

18. Olah, G. A.; Schlosberg, R.H.; Porter, R. D.; MoY, K.; Kelly, D. P,; Mateescu, G. D.; J. Am. Chem. Soc., 1972, 94, 2034-2038.

19. Williams A, Free Energy Relationships in Organic and Bioorganic Chemistry, Royal Society of Chemistry, Cambridge., 2003, 75. 
20. Hückel, E.; Z. Phys., 1931, 70, 204-208.

21. Pratt L, Hydrophobic Effect. In: Amils R. (eds) Encyclopedia of Astrobiology. Springer, Berlin, Heidelberg., 2014.

22. Janas, D.; Stando, G.; Sci. Rep., 2017, 7 12274-12279.

23. Phao, N; Nxumalo, E. N.; Mamba, B. B.; Mhlanga, S. D.; Physics and Chemistry of the
Earth Part A/B/C., 2013, 66, 148- 153.

24. Rachuru, S.; Vandanapu, J.; Rachuru V.V;World Journal of Chemical Education., 2013, 1, 1-5.

25. Briegleb, G.; Z. Elektrochem., 1949, 53, 350-355.

26. Pressman, D.; Siegel, I.; J. Am. Chem. Soc., 1957, 79, 994-997.

27. Jagannadham.V.; Resonance., 2009, 14, 1097-1099. 